This is the final peer-reviewed accepted manuscript of:

Gaspari V, Ortalli M, Foschini MP, Baldovini C, Lanzoni A, Cagarelli R, Gaibani P, Rossini G, Vocale C, Tigani R, Gentilomi GA, Misciali C, Pesci S, Patrizi A, Landini MP, Varani S. New evidence of cutaneous leishmaniasis in north-eastern Italy. J Eur Acad Dermatol Venereol. 2017 Sep;31(9):1534-1540.

The final published version is available online at: http://dx.doi.org/10.1111/jdv.14309

Rights / License:

The terms and conditions for the reuse of this version of the manuscript are specified in the publishing policy. For all terms of use and more information see the publisher's website. 


\section{New evidence of cutaneous leishmaniasis in north-eastern Italy}

\section{Word count}

Text: 3036

N. of Figures: 3

N. of Tables: 2

V. Gaspari MD $\mathrm{PhD}^{1}$, M. Ortalli $\mathrm{MSc}^{2}$, M. P. Foschini $\mathrm{MD}^{3}$, C. Baldovini MD ${ }^{3}$,A. Lanzoni MD ${ }^{4}$, R. Cagarelli $\mathrm{MD}^{5}$, P. Gaibani $\mathrm{PhD}^{6}$, G. Rossini $\mathrm{PhD}^{6}$, C. Vocale $\mathrm{PhD}^{6}$, R. Tigani $\mathrm{MSc}^{6}$, G. A. Gentilomi $\mathrm{PhD}^{7}$, C. Misciali $\mathrm{MD}^{1}$, S. Pesci BSc${ }^{1}$, A. Patrizi MD $\mathrm{PhD}^{1}$, M. P. Landini MD $\mathrm{PhD}^{2,6}$, and S. Varani, $\mathrm{MD} \mathrm{PhD}^{2,6^{*}}$

${ }^{1}$ Unit of Dermatology, Department of Experimental, Diagnostic and Specialty Medicine, University of Bologna, St. Orsola Malpighi University Hospital, Bologna; ${ }^{2}$ Unit of Microbiology, Department of Experimental, Diagnostic and Specialty Medicine, University of Bologna; ${ }^{3}$ Department of Biomedical and Neuro Motor Sciences, Anatomic Pathology "M.Malpighi” at Bellaria Hospital, University of Bologna; ${ }^{4}$ Unit of Dermatology, Bellaria Hospital, Bologna, ${ }^{5}$ Public Health Authority Emilia-Romagna Region, ${ }^{6}$ Regional Reference Center for Microbiological Emergencies (CRREM), Unit of Microbiology, St. Orsola Malpighi University Hospital, Bologna, ${ }^{7}$ Department of Pharmacy and Biotechnology, University of Bologna, Bologna, Italy

*Corresponding author: Stefania Varani, Regional Reference Center for Microbiological Emergencies (CRREM), St. Orsola Malpighi University Hospital, via Massarenti 9, 40138 Bologna Email: stefania.varani@unibo.it; phone: +39 051 2143013; fax: +39 0516363076

Funding: This work was supported by Lab P3 funds from the Emilia-Romagna Region and by RFO 2010-2015 funds (to SV, MPL, AP and MPF) from the University of Bologna.

This item was downloaded from IRIS Università di Bologna (https://cris.unibo.it/)

When citing, please refer to the published version. 
Conflict of interest: The authors declare no conflict of interest

Part of this work was presented at the Italian Society of Microbiology Congress, 25-27 September 2016, Pisa, Italy.

No reprints are requested.

This item was downloaded from IRIS Università di Bologna (https://cris.unibo.it/)

When citing, please refer to the published version. 


\begin{abstract}
Background: Human leishmaniasis is on increase the in Mediterranean Europe. However, the exact prevalence of cutaneous leishmaniasis (CL) is largely unknown as underdiagnosis and underreporting are common.
\end{abstract}

Objective: To evaluate epidemiological, clinicopathological and microbiological aspects of CL cases occurring in the Bologna province, north-eastern Italy.

Methods: We performed a retrospective, observational study on CL cases diagnosed in the Bologna province between January 2013 and December 2015.

Results: During 2013-2015, 30 cases of CL were identified in the Bologna province with an average incidence of 1.00/100,000, with an increase of 4-12 fold as compared to previous years. 16/30 (53\%) CL cases presented as single, typical lesions. CL diagnosis was carried out by histological and molecular techniques, although in 6 out of 29 (21\%) PCR-positive cases amastigotes were not visible on histology.

Conclusions: We report new evidence of CL cases in a focal area of north-eastern Italy in 2013-2015. Our study highlights the importance of CL surveillance in the Mediterranean basin and emphasizes the need for the molecular laboratory surveillance of CL in endemic areas.

Keywords: cutaneous leishmaniasis, clinicopathological diagnosis, molecular diagnosis, laboratory surveillance.

This item was downloaded from IRIS Università di Bologna (https://cris.unibo.it/)

When citing, please refer to the published version. 


\section{Introduction}

Leishmaniasis is a phlebotomine-transmitted infection caused by protozoans belonging to the genus Leishmania; the species L. infantum and L. tropica are endemic in Mediterranean Europe (1), with around 700 autochthonous human cases reported each year (2). Mediterranean leishmaniasis caused by L. infantum is considered a zoonotic infection; humans may enter the zoonotic cycle and contract the infection. Human leishmaniasis may vary from being an asymptomatic to clinically evident infection, which can remain localized in the skin (cutaneous leishmaniasis, CL), extend to the respiratory mucous membranes (mucosal leishmaniasis, ML) or spread throughout the reticuloendothelial system of spleen, liver and bone marrow, thus causing visceral leishmaniasis (VL) (3). Mediterranean tegumentary leishmaniasis includes CL and ML and is caused by L. infantum $(4,5)$.

In CL, the appearance and extent of skin lesions vary depending on the Leishmania species as well as on the host genetic factors and extent of immune response (6). In fact, CL may be pleomorphic in its clinical presentation and generally occurs in an exposed area accessible to sandflies such as the face, neck, arms and limbs. CL lesions can range from a single limited skin lesion that may heal spontaneously to large, multiple and locally destructive skin lesions.

In Mediterranean Europe, CL mainly manifests as a single and painless papule, progressing over weeks to months to a nodule with a central crust; under which an indurated dry ulcer is present (4). Nevertheless, atypical features have been reported for Mediterranean CL, including multiple lesions and erysipeloid, zosteriform or lupoid leishmaniasis (7). Healing may occur over several months and may leave a scar and/or a permanent alteration in the skin pigmentation. Given the chameleon clinical presentation, treatment depends on the aspect of the lesion and the infecting species (8).

ML pathophysiology in the Mediterranean Region remains unclear as it is usually not associated with previous CL (5); the spectrum of clinical manifestations may vary from single to

This item was downloaded from IRIS Università di Bologna (https://cris.unibo.it/)

When citing, please refer to the published version. 
multiple lesions that can manifest as a nodule, tumor, polypoid lesion or granular inflammation and predominantly involve the buccal area (cheeks, lips, hard and soft palate and gums) and the pharyngeal and laryngeal area $(5,9-12)$. Less frequently, the nose can be affected $(5,9-10,12)$.

Since the 1990s, the incidence of human leishmaniasis has been increasing in Italy, with new foci detected within classical endemic areas (southern peninsular regions and islands) and in northern regions previously regarded as non-endemic $(13,14)$. Specifically, the most affected regions for VL include the Tyrrhenian regions, the Adriatic regions and the main islands (Sicily and Sardinia). Sporadic CL cases have also been observed in various Italian regions including north-eastern Italy $(15,16)$, while Sicily is considered to be a hypo-endemic area for CL (7).

Mediterranean VL is gaining interest among physicians and public health experts, while tegumentary leishmaniasis is still neglected, with an underreporting believed to be as high as 2.8-4.6 fold for the European region with compulsory notifiable systems for leishmaniasis (17). Various reasons may explain such underdiagnosis, including the fact that Mediterranean CL is a benign disease and does not usually require hospitalization as well as the misconception that leishmaniasis is a tropical disease, thus remaining unrecognized by general practitioners and most dermatologists (18). Overall, reports on CL in the Mediterranean area are scarce and the exact prevalence of cases is largely unknown.

The aim of this study was to document the incidence of CL, during the time frame January 2013-December 2015, in a localized area of the Bologna Province, north-eastern Italy. Epidemiological, clinico-pathological and microbiological aspects of the CL cases were examined.

\section{Patients and Methods}

Study area

This item was downloaded from IRIS Università di Bologna (https://cris.unibo.it/)

When citing, please refer to the published version. 
The Province of Bologna is located in the northern part of Italy between $44^{\circ} 29^{\prime} 38^{\prime \prime} \mathrm{N}$ and $11^{\circ} 20^{\prime} 34^{\prime \prime} \mathrm{E}$, with an area of $3,702.3 \mathrm{~km}^{2}$. The Province has a population of 1,004,637 inhabitants, with an average population density of 271.4 inhabitants $/ \mathrm{km}^{2}$. The climate is continental and is characterized by cold winter and hot summer temperatures. Geographically, the province comprises two discrete areas: an alluvial plain and the Apennines zone with foothills and mountains, which constitutes $44 \%$ of the total area; these two areas are divided by a large road (Via Aemilia) (19).

\section{Settings and samples}

This study was performed between January 2013 and December 2015. Suspected CL patients with skin lesion(s) were referred to the Dermatology Units at St.Orsola-Malpighi University Hospital and at Bellaria Hospital, Bologna (Italy). Patient information including demographic data, clinical history, size and the number of lesions was recorded on specific forms. A cutaneous biopsy was always performed; histology was carried out at the Dermatopathology Unit, St.Orsola-Malpighi University Hospital and at the Anatomic Pathology Unit at Bellaria Hospital. Punch biopsies and/or paraffinedembedded biopsies from suspected cases of CL were sent to the Regional Reference Center for Microbiological Emergencies (CRREM laboratory, Unit of Microbiology, St.Orsola-Malpighi University Hospital, Bologna) to perform molecular tests. Follow-up visits of patients were programmed at 3,6 and 12 months after treatment to ascertain complete cure.

\section{Diagnosis of CL and case notification}

Case definition was based on the World Health Organization (WHO) (20) directives and on recent literature (21); a case of CL was defined as a patient with suggestive cutaneous lesion/s, in which Leishmania parasites were detected by histology and/or by polymerase chain reaction (PCR). Human leishmaniasis is a compulsory notifiable disease in Italy (17); laboratory-confirmed cases of CL are

This item was downloaded from IRIS Università di Bologna (https://cris.unibo.it/) 
reported by local public health departments to the regional authorities using a standardised notification form.

\section{Histology}

Biopsy specimens were formalin fixed and paraffin embedded following routine procedures. From each block, $2 \mu \mathrm{m}$ sections were obtained and stained with hematoxilyn and eosin (H\&E) for histopathological examination. Special stains such as Giemsa and Periodic Acid Schiff for leishmanial amastigotes were also applied. In addition, all cases showing a granulomatous reaction were investigated with the Ziehl-Neelsen stain in order to exclude mycobacterial infections.

\section{Molecular methods}

Real-time PCR tests were performed on tissue specimens at the CRREM laboratory. DNA was extracted from fresh tissues using the DNAeasy Blood and Tissue kit (Qiagen, Hilden, Germany) and from paraffin-embedded sections $(10 \mu \mathrm{m}$ thickness $)$ by using the NucleoSpin ${ }^{\circledR}$ DNA FFPE XS kit (Macherey-Nagel, Duren, Germany), respectively. Two home-made real-time PCR tests were carried out; a segment of the small-subunit rRNA gene of Leishmania was amplified (22) as well as a segment of the kinetoplast DNA (23). Primers (U1 5'-AAGTGCTTTCCCATCGCAACT-3', U2 5'GACGCACTAAACCCCTCCAA-3' for rRNA PCR; 15 pmol of RV1 5'-

CTTTTCTGGTCCTCCGGGTAGG-3', 15 pmol of RV2 5'-
CCACCCGGCCCTATTTTACACCAA-3' for kDNA PCR) were synthesized by Primm Biotech (Milan, Italy) and 50 pmol of TaqMan probes (FAM-CGGTTCGGTGTGTGGCGCC-TAMRA and FAM-TTTTCGCAGAACGCCCCTACCCGC-TAMRA for rRNA PCR and kDNA PCR, respectively) were synthesized by IDTDNA (Leuven, Belgium). The real-time PCR assays were performed by employing the CFX Real Time PCR detection System (Bio-Rad, California, USA). $\beta 2$ -

This item was downloaded from IRIS Università di Bologna (https://cris.unibo.it/)

When citing, please refer to the published version. 
microglobulin real-time PCR assay was run simultaneously as a control of amplification of the extracted DNA.

\section{Treatments}

Several treatments were performed, according to localization, number, size and disfiguring potential of the lesion. The therapeutic options included 1.topical cream containing paromomycin sulphate $15 \%$ formulated in $10 \%$ urea in white soft paraffin (applied twice daily for 6 months); 2 . intralesional injections of pentavalent antimonials (one injection every 7 days for a total of 4 infiltrations); 3 . cryotherapy (topical applications of liquid nitrogen with a cotton-tipped applicator or a cotton swab with moderate pressure to the lesion, up to $2 \mathrm{~mm}$ outside the lesion margin, every 3 weeks for 3 months), often associated with intralesional pentavalent antimonials or with topical paromomycin $15 \%$; 4. oral fluconazole (200 mg twice a day for 6 weeks) associated with local treatment (cryotherapy and topical paromomycin 15\%). In a few cases, patients underwent surgical excision. Patients were followed up for one year after treatment (visits at 3, 6 and 12 months).

This item was downloaded from IRIS Università di Bologna (https://cris.unibo.it/) 


\section{Results}

Patient characteristics and case distribution

In the study period (January 2013 to December 2015) 30 cases of CL were identified in the Bologna Province, including 5 cases in 2013, 15 cases in 2014 and 10 in 2015, whereas in 2008-2012 the average number of cases per year was 1.2 (range of 0-3). CL incidence was 0.50/100,000 in 2013, $1.49 / 100,000$ in 2014 and $1.00 / 100,000$ in 2015 , respectively. The geographical case distribution is reported in Figure 1a. The age of CL affected patients ranged from 2 to 87 years, with a median age of 56 years; all but 6 cases occurred in adults, with only 7 patients under 30 years of age (Figure 1b). The female-to-male ratio was 9/21. No seasonality was evident in case detection (Figure 2). However, by estimating the time of lesion onset on the basis of patient's history, we observed that the onset of CL cases was more frequent (67\%) in the second part of the year (July-December).

\section{Clinicopathological features}

The head and neck area was the most common location for the cutaneous lesions $(n=20)$, followed by the upper $(\mathrm{n}=7)$ and lower extremities $(\mathrm{n}=3)$ (Table 1$) . \mathrm{N}=22$ out of 30 patients $(73.3 \%)$ exhibited a single lesion, while multiple lesions were present in the remaining 8 patients, with a maximum of 3 lesions per patient. Lesion size ranged from $1.5 \mathrm{~cm}_{2}$ to $10.0 \mathrm{~cm}_{2}$ (median $3.5 \mathrm{~cm}_{2}$ ). Plaque or nodular lesions, with or without ulceration, were the most common lesion type (Figure 3). They were present in 26 out of $30(86.6 \%)$ patients, while 4 atypical lesions were observed, including multiple zosteriform nodules in one patient (case nr. 2, Figure 3d), a single eroded papule in patient nr. 27, a single trophic ulcer in case nr. 30 and a basocellular carcinoma-like nodule in case $\mathrm{nr}$. 25, as shown in Table 1. Most patients (17 cases) exhibited an erythematous plaque or a nodule without ulceration; in 10 cases primary lesions were a plaque or a nodule with ulceration and 3 exhibited both ulceration

This item was downloaded from IRIS Università di Bologna (https://cris.unibo.it/)

When citing, please refer to the published version. 
and erythema. No cases were known to be HIV-positive. When presenting to the Dermatology Unit, all patients had active lesions without evidence of healing or scarring.

\section{Histopathology}

Twenty-six biopsy specimens from 26 patients were reviewed, while the remaining four cases of the series were not available for a second histopathology analysis. Histopathological features are summarized in Table 2. The most common epidermal changes were hyperkeratosis (24/26 cases) and parakeratosis (17/26), often associated with exocytosis (17/26) and basal cell vacuolization (19/26). Within the dermis, a mononuclear infiltration of lymphocytes, histiocytes and plasma cells, admixed with occasional eosinophils was constantly present (26/26 cases). Well-formed non necrotizing granulomas were found in 17/26 cases, often associated with multinucleated giant cells (15/26). However, 13/26 cases displayed a non-specific granulomatous tissue reaction characterized by dermal aggregates of epithelioid and foamy macrophages.

\section{Diagnosis}

CL was identified in a median time of 6 months from lesion onset (range: 2-14) and diagnosis was accomplished by histological and molecular tools (Table 1). Intracytoplasmic amastigotes were detected in 23 of 30 cases (76.7\%). When considering only the reviewed cases, 17 of the 26 cases exhibited amastigotes with H\&E and Giemsa (Table 2). Leishmanial DNA was detected in 7 additional patients for whom the diagnosis was clinically and histologically suspected, but no leishmanial amastigotes were found. In one patient PCR was not performed.

\section{Treatment and outcome}

Treatment options were: 1 . topical cream containing paromomycin $(n=7), 2$. intralesional pentavalent antimonials $(n=3), 3$. cryotherapy associated with intralesional pentavalent antimonials $(n=7)$ or with

This item was downloaded from IRIS Università di Bologna (https://cris.unibo.it/)

When citing, please refer to the published version. 
topical paromomycin $15 \%(n=3), 4$. oral fluconazole associated with local treatment (cryotherapy and topical paromomycin 15\%) $(n=2)$, 5. surgical excision $(n=5)$. Systemic therapy (fluconazole) was prescribed in two patients (patient nr. 1 and nr. 16, Table 1), because of the size and the localization of the lesions; CL was localized in the face of patient nr. 1, which is a potentially disfiguring site, and in the elbow of patient nr. 16, which can cause joint-related functional impairment if not properly treated.

Apart from those subjected to surgical excision, the cutaneous lesions of most patients $(n=15)$ healed on average in 6 months (range 1-12 months); 7 patients were free of disease in 3 months, while 3 other patients were lost at follow up. Relapse of CL was observed in two cases (patient nr. 15 and patient nr. 24, Table 1). After relapse, the lesions healed following treatment with intralesional antimonials. Follow-up of these two patients is ongoing.

This item was downloaded from IRIS Università di Bologna (https://cris.unibo.it/) 


\section{Discussion}

The emergence of exotic vector-borne viral diseases in Europe as a consequence of global warming and globalization has raised wide concern in recent years, whereas the resurgence of autochthonous vector-borne parasitoses, such as leishmaniasis, has been of lesser impact at the European public health policy level (2). This is particularly true for the cutaneous form of leishmanial disease, which is often ignored and unrecognized by clinicians and for which underreporting is common (18).

We detected an increasing number of CL cases in the Bologna Province in 2013-2015; CL incidence was $0.50 / 100,000$ in $2013,1.49 / 100,000$ in 2014 and $1.00 / 100,000$ in 2015 , respectively, as compared to an average incidence of 0.12/100,000 in 2008-2012 (24), indicating an increase of 412 fold of identified cases in recent years. All but four cases were gathered in a sort of "leishmaniasis belt" that was localized south of the Via Aemilia, with a cluster of 7 cases in a single municipality (Valsamoggia, Figure 1a).

This rise in CL cases is possibly related to the increased circulation of the leishmanial parasite in the examined region, since an escalation of VL cases was recently reported in the same area (25). Nevertheless, we believe that improved molecular diagnosis as well as increased awareness among dermatologists of this area contributed to the higher number of notified CL cases in recent years. As a matter of fact, during the study period real-time PCR became a routine diagnostic procedure for CL at the Regional Reference laboratory for human leishmaniasis, thus facilitating diagnosis.

Detection of the parasites in tissue sections of patients may be difficult when only few leishmanial amastigotes are present. Moreover, histology of the present cases underlined that CL may display a broad spectrum of morphological patterns, often with nonspecific features. Therefore, when amastigotes are not promptly identified, histological findings may be mistaken for nonspecific chronic inflammation and/or granulomatous reactions (26).

This item was downloaded from IRIS Università di Bologna (https://cris.unibo.it/)

When citing, please refer to the published version. 
Recent evidence suggests that PCR is a highly sensitive and specific method to detect leishmanial DNA in dermal biopsies $(15,21,26)$. In our study, real-time PCR enabled the diagnosis of 7 cases of CL, which classical histology had failed to identify. Thus, PCR for leishmanial-specific DNA should be performed routinely not only in typical lesions, but also in any unusual dermatosis, in particular those showing a huge dermal granulomatous infiltrate. Particular attention should be taken with patients coming from areas where the parasite circulates.

We observed that the median time between symptom onset and CL diagnosis was 6 months (range 2-14); this delayed diagnosis may be related both to the patient (delay in seeking care for a benign disease) and to the healthcare system (clinician, dermatologist and dermopathologist did not suspect the aetiology).

Clinical features were typical for Mediterranean CL in most of the examined patients; $73.3 \%$ of cases exhibited a single nodular lesion or a plaque, while multifocality was detected in the remaining patients. The male to female ratio indicated that the infection rate among males was higher than females (2.3:1.0), which is in line with published data (20).

We observed that most CL lesions had their onset during the second part of the year. This is in line with previous reports of CL in the Mediterranean basin (4), where the diagnosis is usually made in autumn or winter because patients are infected during summer, the period of activity of phlebotomine sandflies (27). However, one should take into account the enormous variability in the incubation period, which can last from less than 1 month to more than 2 years (20).

Current CL management is for a considerable part non-evidence based and most therapy options have to rely on expert opinions (21). Even though Mediterranean CL is often self-limiting, treatment is necessary to accelerate the healing process, to reduce significant scarring and to decrease relapse $(28,29)$. Treatment of CL differs from one patient to another, and depends on the clinical aspect of the lesion and the infecting species.

This item was downloaded from IRIS Università di Bologna (https://cris.unibo.it/)

When citing, please refer to the published version. 
Local treatment proved to be well tolerated and with high cure rates, and includes topical treatment with $15 \%$ paromomycin, cryotherapy, thermotherapy and intralesional injection with antimonials $(21,30)$. Systemic treatment includes miltefosine, fluconazole, liposomal amphotericin B, systemic pentavalent antimonial or systemic pentavalent antimonial and pentoxifylline (12, 21, $30)$.

The choice of topical or systemic treatment is determined by several factors, such as the risk of mucosal spreading of the infection, the size, number and localization of lesions and the failure of prior local treatment (31). With regards to the clinical features, the multiple and large lesions that affect the nose, lips, eyelids or ears, which are cosmetically disfiguring, or that are located close to small joints, are less suited to local therapy. Nevertheless, criteria for selecting therapeutic options are not clearly validated and there is a need for large clinical trials to define treatment guidelines and standardization of the treatment for CL.

In our study cohort, considering that 1 . most of the lesions were single, $<4 \mathrm{~cm}$ in diameter, popular/nodular lesions, 2. the patients were immunocompetent, 3. there were no signs of lymphangitic dissemination and 4. the risk of mucosal spreading was low, we chose local treatment with antimonials, paromomycin, cryotherapy or a combination of these in all but two cases. Local injection of antimonials associated with cryotherapy or paromomycin $15 \%$ are good option that offer less systemic toxicity and the possibility for ambulatory treatment. In the lesions of esthetically compromised areas (eyelids, lips) cryotherapy should be used carefully to avoid the generation of blisters. In two cases systemic therapy was performed because of potentially disfiguring lesion (patient nr. 1) or the risk of joint-related functional impairment (patient nr. 16) $(32,33)$. All the treatment options led to lesion disappearance, but relapse occurred in two cases; relapsed CL healed after treatment with intralesional antimonials.

This item was downloaded from IRIS Università di Bologna (https://cris.unibo.it/) 
In conclusion, we report new evidence of CL cases in a focal area of north-eastern Italy during the period 2013-2015. The molecular identification of Leishmania species for this cluster as well as the evaluation of strain characteristics are ongoing. Our study shows that CL is endemic in the Bologna province, north-eastern Italy, and highlights the importance of CL surveillance in the Mediterranean basin. Furthermore, molecular diagnosis should be included in algorithms for the identification of CL cases to improve diagnostic sensitivity.

This item was downloaded from IRIS Università di Bologna (https://cris.unibo.it/) 


\section{References}

1. Ready PD. Leishmaniasis emergence in Europe. Euro Surveill. 2010;15(10):19505.

2. Dujardin JC, Campino L, Cañavate C, Dedet JP, Gradoni L, Soteriadou K, et al. Spread of vector-borne diseases and neglect of Leishmaniasis, Europe. Emerg Infect Dis. 2008;14(7):1013-8.

3. Murray HW, Berman JD, Davies CR, Saravia NG. Advances in leishmaniasis. Lancet. 2005;366(9496):1561-77.

4. del Giudice P, Marty P, Lacour JP, Perrin C, Pratlong F, Haas H, et al. Cutaneous leishmaniasis due to Leishmania infantum. Case reports and literature review. Arch Dermatol. 1998;134(2):193-8.

5. Faucher B, Pomares C, Fourcade S, Benyamine A, Marty P, Pratlong L, et al. Mucosal Leishmania infantum leishmaniasis: specific pattern in a multicentre survey and historical cases. J Infect. 2011;63(1):76-82.

6. Reithinger R, Dujardin JC, Louzir H, Pirmez C, Alexander B, Brooker S. Cutaneous leishmaniasis. Lancet Infect Dis. 2007;7(9):581-96.

7. Bongiorno MR, Pistone G, Aricò M. Unusual clinical variants of cutaneous leishmaniasis in Sicily. Int J Dermatol. 2009;48(3):286-9.

8. Blum J, Buffet P, Visser L, Harms G, Bailey MS, Caumes E, et al. LeishMan recommendations for treatment of cutaneous and mucosal leishmaniasis in travelers, 2014. J Travel Med. 2014;21(2):116-29.

9. Aliaga L, Cobo F, Mediavilla JD, Bravo J, Osuna A, Amador JM, et al. Medicine (Baltimore). 2003;82(3):147-58. Localized mucosal leishmaniasis due to Leishmania (Leishmania) infantum: clinical and microbiologic findings in 31 patients.

This item was downloaded from IRIS Università di Bologna (https://cris.unibo.it/)

When citing, please refer to the published version. 
10. Richter J, Hanus I, Häussinger D, Löscher T, Harms G. Mucosal Leishmania infantum infection. Parasitol Res. 2011;109(3):959-62.

11. Mignogna MD, Celentano A, Leuci S, Cascone M, Adamo D, Ruoppo E, et. Al.

Mucosal leishmaniasis with primary oral involvement: a case series and a review of the literature. Oral Dis. 2015;21(1):e70-8.

12. Mosimann V, Blazek C, Grob H, Chaney M, Neumayr A, Blum J. Miltefosine for Mucosal and Complicated Cutaneous Old World Leishmaniasis: A Case Series and Review of the Literature. Open Forum Infect Dis. 2016;3(1):ofw008.

13. Maroli M, Rossi L, Baldelli R, Capelli G, Ferroglio E, Genchi C, et al. The northward spread of leishmaniasis in Italy: evidence from retrospective and ongoing studies on the canine reservoir and phlebotomine vectors. Trop Med Int Health. 2008;13(2):256-64.

14. Gramiccia M, Scalone A, Di Muccio T, Orsini S, Fiorentino E, Gradoni L. The burden of visceral leishmaniasis in Italy from 1982 to 2012: a retrospective analysis of the multi-annual epidemic that occurred from 1989 to 2009. Euro Surveill. 2013;18(29):20535.

15. Tordini G, Giaccherini R, Pacenti L, Miracco C, Zazzi M, Zanelli G. Cutaneous leishmaniasis: usefulness of PCR on paraffin-embedded skin biopsies as part of routine investigation. Ann Trop Med Parasitol. 2007;101(8):745-9.

16. Calderaro A, Montecchini S, Rossi S, Gorrini C, Dell'Anna ML, Piccolo G, et al. A 22-year survey of leishmaniasis cases in a tertiary-care hospital in an endemic setting. Int J Environ Res Public Health. 2014;11(3):2834-45.

17. Alvar J, Vélez ID, Bern C, Herrero M, Desjeux P, Cano J, et al. Leishmaniasis worldwide and global estimates of its incidence. PLoS One. 2012;7(5):e35671.

18. Gradoni L. Epidemiological surveillance of leishmaniasis in the European Union: operational and research challenges. Euro Surveill. 2013;18(30):20539.

This item was downloaded from IRIS Università di Bologna (https://cris.unibo.it/)

When citing, please refer to the published version. 
19. Bologna Province, ARPA Emilia-Romagna. La Certificazione ambientale nell'Appennino Bolognese. Analisi ambientale iniziale; 2004 (online). Available at https://www.arpae.it/cms3/documenti/_cerca_doc/certificazioni/analisi_amb_iniziale_com_\%20mo $\underline{\text { nt.pdf }}$ (Last accessed March 16, 2017)

20. WHO. Control of the leishmaniases: report of a meeting of the WHO Expert Committee on the Control of Leishmaniases, Geneva, 22-26 March 2010 (online). 2010. Available at http://apps.who.int/iris/bitstream/10665/44412/1/WHO TRS 949 eng.pdf (last accessed March 16, 2017).

21. de Vries HJ, Reedijk SH, Schallig HD. Cutaneous leishmaniasis: recent developments in diagnosis and management. Am J Clin Dermatol. 2015;16(2):99-109.

22. Wortmann G, Sweeney C, Houng HS, Aronson N, Stiteler J, Jackson J, et al. Rapid diagnosis of leishmaniasis by fluorogenic polymerase chain reaction. Am J Trop Med Hyg. 2001;65(5):583-7. 23. Mary C, Faraut F, Lascombe L, Dumon H. Quantification of Leishmania infantum DNA by a real-time PCR assay with high sensitivity. J Clin Microbiol. 2004;42(11):5249-55.

24. Leishmaniasis in Emilia-Romagna Region; surveillance system results: Public Health Authority Emilia Romagna; 2015 (online). Available at http://salute.regione.emiliaromagna.it/documentazione/rapporti/201cleishmaniasis-in-emilia-romagna-region-surveillancesystem-results201d (last accessed March 16, 2017).

25. Varani S, Cagarelli R, Melchionda F, Attard L, Salvadori C, Finarelli AC, et al. Ongoing outbreak of visceral leishmaniasis in Bologna Province, Italy, November 2012 to May 2013. Euro Surveill. 2013;18(29):20530.

26. Martín-Ezquerra G, Fisa R, Riera C, Rocamora V, Fernández-Casado A, Barranco C, et al. Role of Leishmania spp. infestation in nondiagnostic cutaneous granulomatous lesions: report of a series of patients from a Western Mediterranean area. Br J Dermatol. 2009;161(2):320-5.

This item was downloaded from IRIS Università di Bologna (https://cris.unibo.it/)

When citing, please refer to the published version. 
27. Alten B, Maia C, Afonso MO, Campino L, Jiménez M, González E, et al. Seasonal Dynamics of Phlebotomine Sand Fly Species Proven Vectors of Mediterranean Leishmaniasis Caused by Leishmania infantum. PLoS Negl Trop Dis. 2016;10(2):e0004458.

28. Palumbo E. Current treatment for cutaneous leishmaniasis: a review. Am J Ther. 2009;16(2):178-82.

29. Ameen M. Cutaneous leishmaniasis: advances in disease pathogenesis, diagnostics and therapeutics. Clin Exp Dermatol. 2010;35(7):699-705.

30. Blum J, Desjeux P, Schwartz E, Beck B, Hatz C. Treatment of cutaneous leishmaniasis among travellers. J Antimicrob Chemother. 2004;53(2):158-66.

31. Blum J. LeishMan: harmonising diagnostic and clinical management of leishmaniasis in Europe. Euro Surveill. 2013;18(30):20538.

32. Monge-Maillo B, López-Vélez R. Therapeutic options for old world

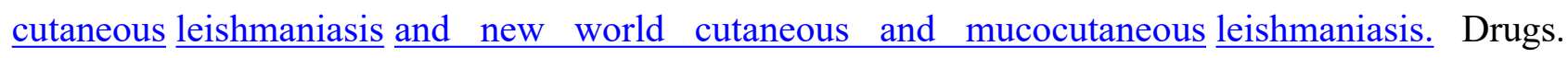
2013;73(17):1889-920.

33. Pace D. Leishmaniasis. J Infect. 2014;69 Suppl 1:S10-8.

This item was downloaded from IRIS Università di Bologna (https://cris.unibo.it/)

When citing, please refer to the published version. 
Table 1. Clinical and parasitological features of cutaneous leishmaniasis, Bologna Province, Italy , 2013-2015

\begin{tabular}{|c|c|c|c|c|c|c|c|c|c|}
\hline $\begin{array}{c}\text { Case } \\
\text { nr }\end{array}$ & Sex & Age & $\begin{array}{l}\text { Localization of } \\
\text { lesion } \\
\text { (single/multiple) }\end{array}$ & Type of lesion & $\begin{array}{c}\text { Histolog } \\
\mathbf{y}\end{array}$ & PCR & $\begin{array}{c}\text { Time to } \\
\text { diagnosi } \\
\text { s } \\
\text { (months) }\end{array}$ & $\begin{array}{c}\text { Treatmen } \\
\mathbf{t}\end{array}$ & $\begin{array}{c}\text { Cure } \\
\text { d } \\
(\mathrm{Y} / \mathrm{N})\end{array}$ \\
\hline 1 & M & 17 & Face (s) & $\begin{array}{l}\text { Erythematous } \\
\text { nodule }\end{array}$ & POS & POS & 6 & cry, par, flu & $\mathrm{Y}$ \\
\hline 2 & M & 73 & Forehead (m) & Zosteriform nodules & POS & POS & 3 & $\begin{array}{l}\text { antimonials } \\
\text { (glucantim) }\end{array}$ & $\mathrm{Y}$ \\
\hline 3 & $\mathrm{~F}$ & 66 & Face (m) & Ulcerated plaque & POS & POS & 7 & par & $\mathrm{Y}$ \\
\hline 4 & $\mathrm{~F}$ & 54 & Cheek (m) & $\begin{array}{l}\text { Erythematous } \\
\text { nodule }\end{array}$ & POS & POS & 8 & $\begin{array}{l}\text { cry, } \\
\text { antimonials }\end{array}$ & $\mathrm{Y}$ \\
\hline 5 & M & 28 & Wrist (s) & Plaque & POS & POS & 12 & par & $\mathrm{Y}$ \\
\hline 6 & $\mathrm{~F}$ & 87 & Arm (s) & Nodule & POS & POS & 6 & $\begin{array}{c}\text { cry, } \\
\text { antimonials }\end{array}$ & $\mathrm{Y}$ \\
\hline 7 & M & 69 & Cheek (s) & Ulcerated plaque & POS & POS & 6 & $\begin{array}{c}\text { cry, } \\
\text { antimonials }\end{array}$ & $\mathrm{Y}$ \\
\hline 8 & M & 77 & Scalp (s) & $\begin{array}{l}\text { Erythematous } \\
\text { nodule }\end{array}$ & POS & POS & 3 & antimonials & $\mathrm{Y}$ \\
\hline 9 & $\mathrm{~F}$ & 78 & Forehead (s) & Ulcerated nodule & POS & POS & 4 & par & $\mathrm{Y}$ \\
\hline 10 & M & 51 & $\operatorname{Arm}(\mathrm{s})$ & $\begin{array}{l}\text { Erythematous } \\
\text { nodule }\end{array}$ & NEG & POS & 6 & $\begin{array}{l}\text { lesion } \\
\text { excision }\end{array}$ & $\mathrm{Y}$ \\
\hline 11 & M & 57 & Hand (s) & $\begin{array}{l}\text { Erythematous } \\
\text { nodule }\end{array}$ & POS & POS & 3 & $\begin{array}{l}\text { lost at } \\
\text { follow up }\end{array}$ & ND \\
\hline 12 & M & 70 & Scalp (s) & $\begin{array}{l}\text { Erythematous } \\
\text { plaque }\end{array}$ & POS & N.D & 12 & cry, par & $\mathrm{Y}$ \\
\hline 13 & M & 68 & Neck (s) & Nodule & NEG & POS & 12 & $\begin{array}{l}\text { lost at } \\
\text { follow up }\end{array}$ & ND \\
\hline 14 & M & 64 & Trunk (m) & $\begin{array}{l}\text { Erythematous } \\
\text { nodule }\end{array}$ & POS & POS & 3 & $\begin{array}{l}\text { lost at } \\
\text { follow up }\end{array}$ & ND \\
\hline 15 & $\mathrm{~F}$ & 63 & Cheek (s) & $\begin{array}{l}\text { Erythematous } \\
\text { plaque }\end{array}$ & POS & POS & 6 & $\begin{array}{l}\text { cry, } \\
\text { antimonials }\end{array}$ & FU* \\
\hline 16 & M & 61 & Elbow (m) & Nodule & NEG & POS & 14 & cry, par, flu & $\mathrm{Y}$ \\
\hline 17 & M & 58 & Eyelid (s) & Plaque & NEG & POS & 5 & par & $\mathrm{Y}$ \\
\hline 18 & M & 34 & Scalp (s) & Ulcerated nodule & POS & POS & 9 & $\begin{array}{c}\text { cry, } \\
\text { antimonials }\end{array}$ & $\mathrm{Y}$ \\
\hline 19 & M & 75 & Knee (m) & Ulcerated nodule & POS & POS & 2 & $\begin{array}{c}\text { cry, } \\
\text { antimonials }\end{array}$ & $\mathrm{Y}$ \\
\hline 20 & $\mathrm{~F}$ & 46 & $\operatorname{Lip}(s)$ & Nodule & POS & POS & 12 & par & $\mathrm{Y}$ \\
\hline 21 & M & 7 & Forehead (s) & $\begin{array}{l}\text { Erythemato- } \\
\text { ulcerated plaque }\end{array}$ & POS & POS & 8 & $\begin{array}{c}\text { cry, } \\
\text { antimonials }\end{array}$ & $\mathrm{Y}$ \\
\hline 22 & M & 82 & $\operatorname{Arm}(\mathrm{m})$ & $\begin{array}{c}\text { Erythemato- } \\
\text { squamous plaque }\end{array}$ & POS & POS & 12 & cry, par & $\mathrm{Y}$ \\
\hline 23 & M & 38 & Forehead (s) & Itchy nodule & NEG & POS & 6 & antimonials & $\mathrm{Y}$ \\
\hline 24 & M & 55 & Nape (s) & $\begin{array}{l}\text { Erythemato-eroded } \\
\text { plaque }\end{array}$ & POS & POS & 12 & cry, par & FU* \\
\hline 25 & $\mathrm{~F}$ & 32 & Forehead (s) & $\begin{array}{c}\text { Basocellular } \\
\text { carcinoma-like } \\
\text { nodule(s) }\end{array}$ & NEG & POS & 4 & $\begin{array}{l}\text { lesion } \\
\text { excision }\end{array}$ & $\mathrm{Y}$ \\
\hline 26 & M & 12 & Leg (s) & Ulcerated nodule & POS & POS & 6 & par & $\mathrm{Y}$ \\
\hline 27 & $\mathrm{~F}$ & 4 & Face (s) & Eroded papule & POS & POS & 8 & par & $\mathrm{Y}$ \\
\hline
\end{tabular}

This item was downloaded from IRIS Università di Bologna (https://cris.unibo.it/)

When citing, please refer to the published version. 


\begin{tabular}{|c|c|c|c|c|c|c|c|c|c|}
\hline 28 & M & 37 & $\begin{array}{l}\text { Cheek and nose } \\
\text { (m) }\end{array}$ & Ulcerated plaque & NEG & POS & 2 & $\begin{array}{l}\text { lesion } \\
\text { excision }\end{array}$ & $\mathrm{Y}$ \\
\hline 29 & $\mathrm{~F}$ & 2 & Eyelid (s) & Eroded nodule & POS & POS & 4 & $\begin{array}{l}\text { lesion } \\
\text { excision }\end{array}$ & $\mathrm{Y}$ \\
\hline 30 & M & 8 & Thigh (s) & Trophic ulcer & POS & POS & 3 & $\begin{array}{l}\text { lesion } \\
\text { excision }\end{array}$ & $\mathrm{Y}$ \\
\hline
\end{tabular}

Cry, cryotherapy; Par, topic paramomycin; Flu, oral fluconazole $200 \mathrm{mg}$; antimonials, intralesional pentavalent antimonials; nd, not determined

*FU; follow up is ongoing after treatment of relapse 
Table 2. Histopathological findings of cutaneous leishmaniasis ( $\mathrm{n}=26$ cases)

\begin{tabular}{ll}
\hline Characteristics & n (\%) \\
\hline Epidermal changes & \\
Atrophy & $13(50)$ \\
Hyperkeratosis & $24(92)$ \\
Parakeratosis & $17(65)$ \\
Spongiosis & $9(35)$ \\
Basal vacuolization & $19(73)$ \\
Exocytosis & $17(65)$ \\
Ulceration & $6(23)$ \\
Flogistic infiltrate & \\
Perivascular superficial & $4(15)$ \\
Diffuse superficial & $21(81)$ \\
Perivascular deep & $7(27)$ \\
Diffuse deep & $15(58)$ \\
Cytologic composition & \\
Giant cells & $15(58)$ \\
Lymphocytes & $26(100)$ \\
Histiocytes & $26(100)$ \\
PMN & $8(31)$ \\
Plasma cells & $26(100)$ \\
Granulomatous pattern & \\
Tuberculoid & $9(35)$ \\
Sarcoid-like & $8(31)$ \\
Necrosis & $0(0)$ \\
Non specific histiocytic aggregates & $13(50)$ \\
Presence of amastigotes & $17(65)$ \\
\hline PMN, polympon & \\
\hline
\end{tabular}

PMN, polymorphonuclear leukocytes (neutrophils and eosinophils)

This item was downloaded from IRIS Università di Bologna (https://cris.unibo.it/)

When citing, please refer to the published version. 
Figure legends

Figure 1. Distribution of human cases of cutaneous leishmaniasis, Bologna Province, northeastern Italy, January 2013 to December 2015 (n=30). (a). Geographical location of human cases of cutaneous leishmaniasis. The grey area depicts the municipality of Bologna. (b). Distribution of cases of cutaneous leishmaniasis by age and sex.

Figure 2. Seasonal distribution of cutaneous leishmaniasis during 2013-2015, Bologna Province, north-eastern Italy. Cutaneous leishmaniasis (CL) cases were recorded at diagnosis during 2013 (dark blue histograms), 2014 (light blue histograms) and 2015 (grey histograms). Estimated lesion onset based on clinical files is also reported (table and green line).

Figure 3. Clinical features of cutaneous leishmaniasis, Bologna Province, north-eastern Italy, 2013-2015. (a). Single ulcerated plaque; (b). Erythematous-squamous plaque; (c). Erythematous nonulcerated plaque; (d). Zosteriform plaque; (e). Ulcerated nodule; (f). Nodule.

This item was downloaded from IRIS Università di Bologna (https://cris.unibo.it/)

When citing, please refer to the published version. 
(a)

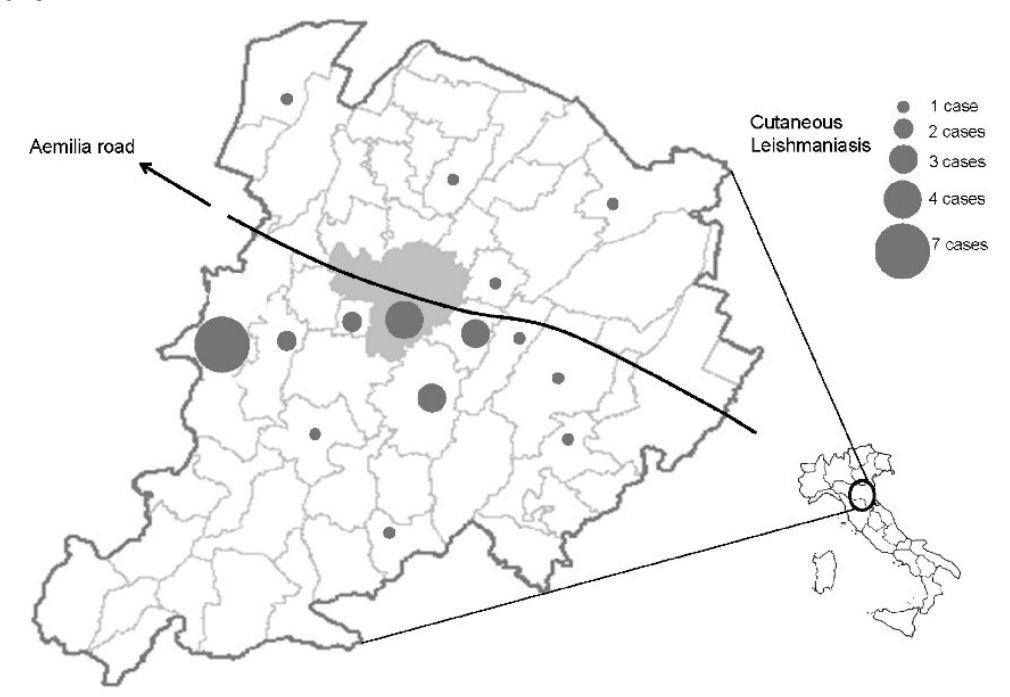

(b)

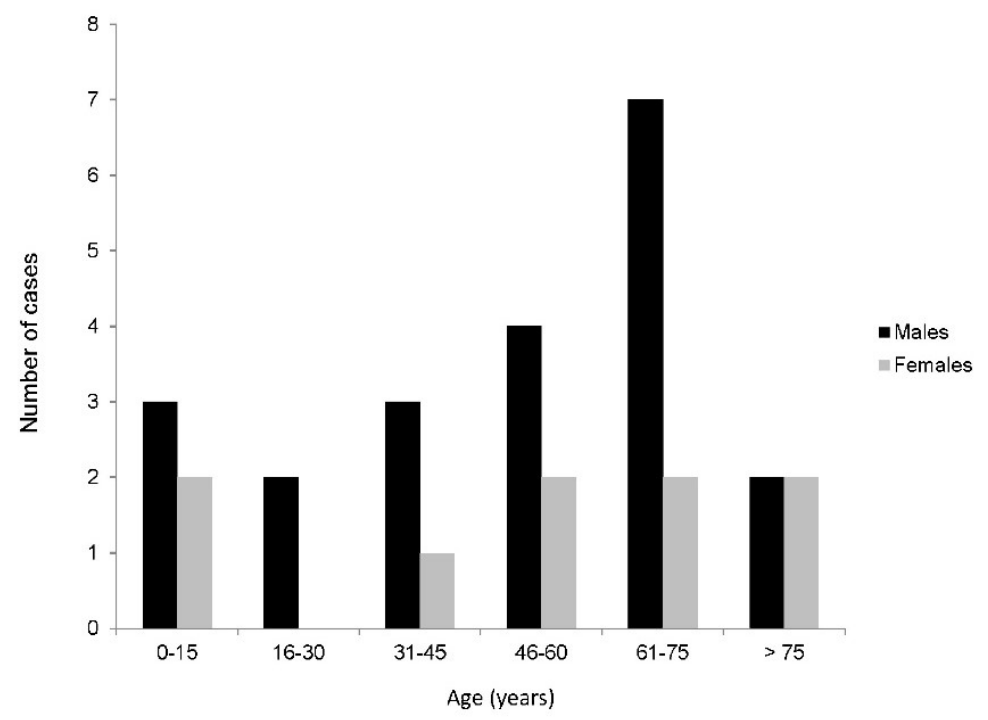

Figure 1 


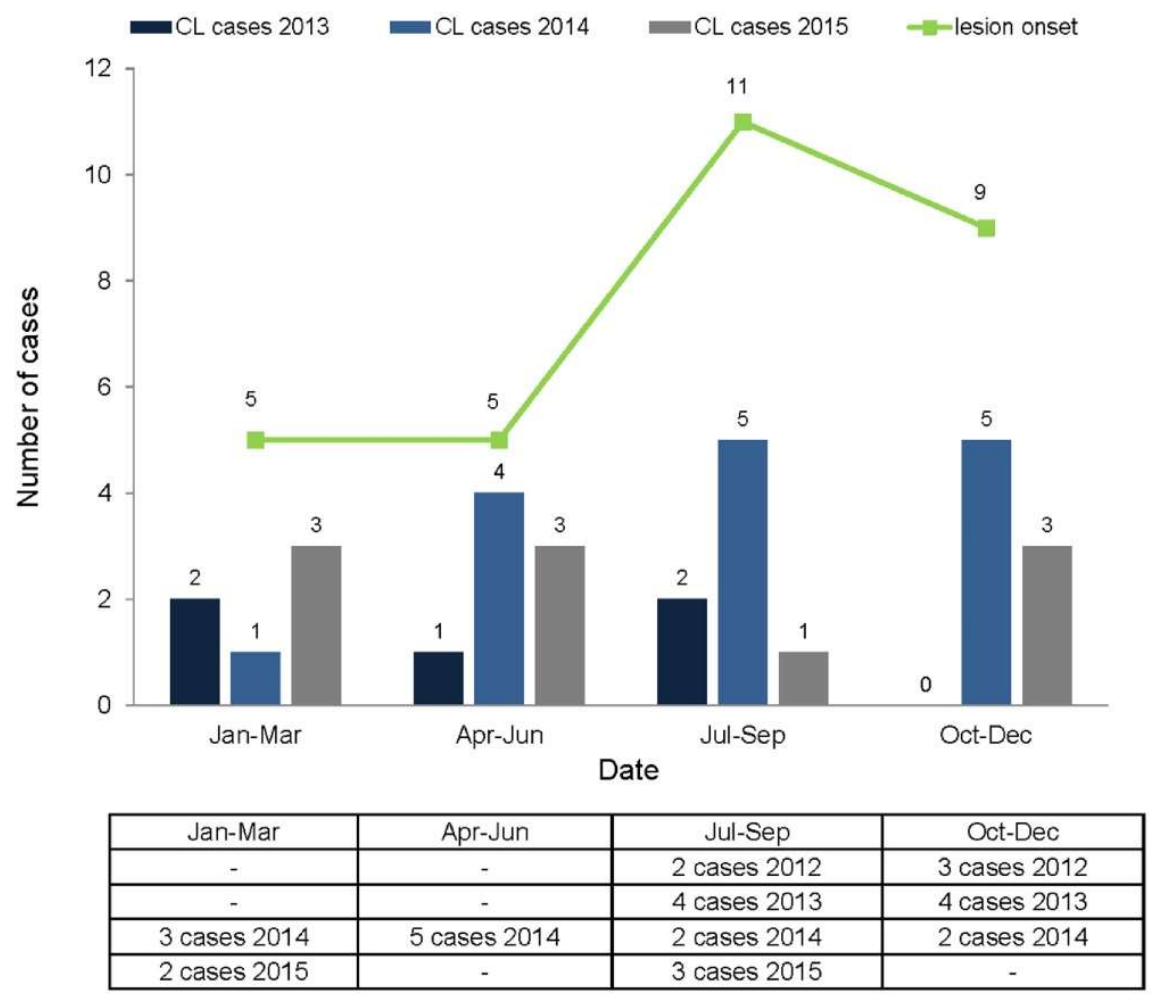

Figure 2 


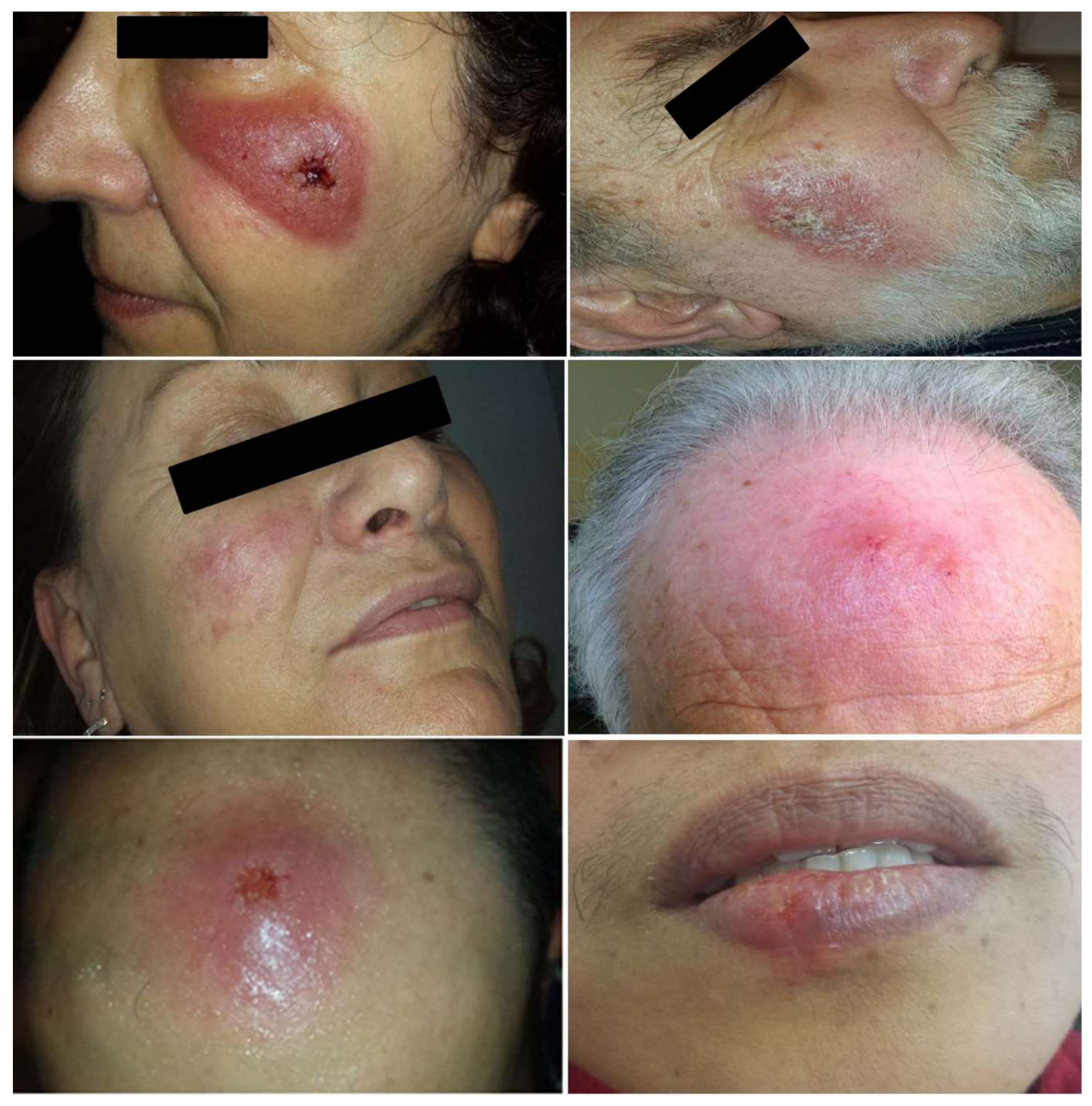

Figure 3

This item was downloaded from IRIS Università di Bologna (https://cris.unibo.it/)

When citing, please refer to the published version. 